\title{
CONF-9504/2--56
}

UCRL-JC-118959

PREPRINT

\section{An In Situ Electron Microscopy Technique for the Study of Thermally Activated Reactions In Multilayered Materials}

M. A. Wall

T. W. Barbee, Jr.

T. P. Weihs

RECENED

NOV -79995

OSTI

This paper was prepared for submittal to MRS 1995 Spring Meeting, San Francisco, CA

April 17-21, 1995

April 14, 1995

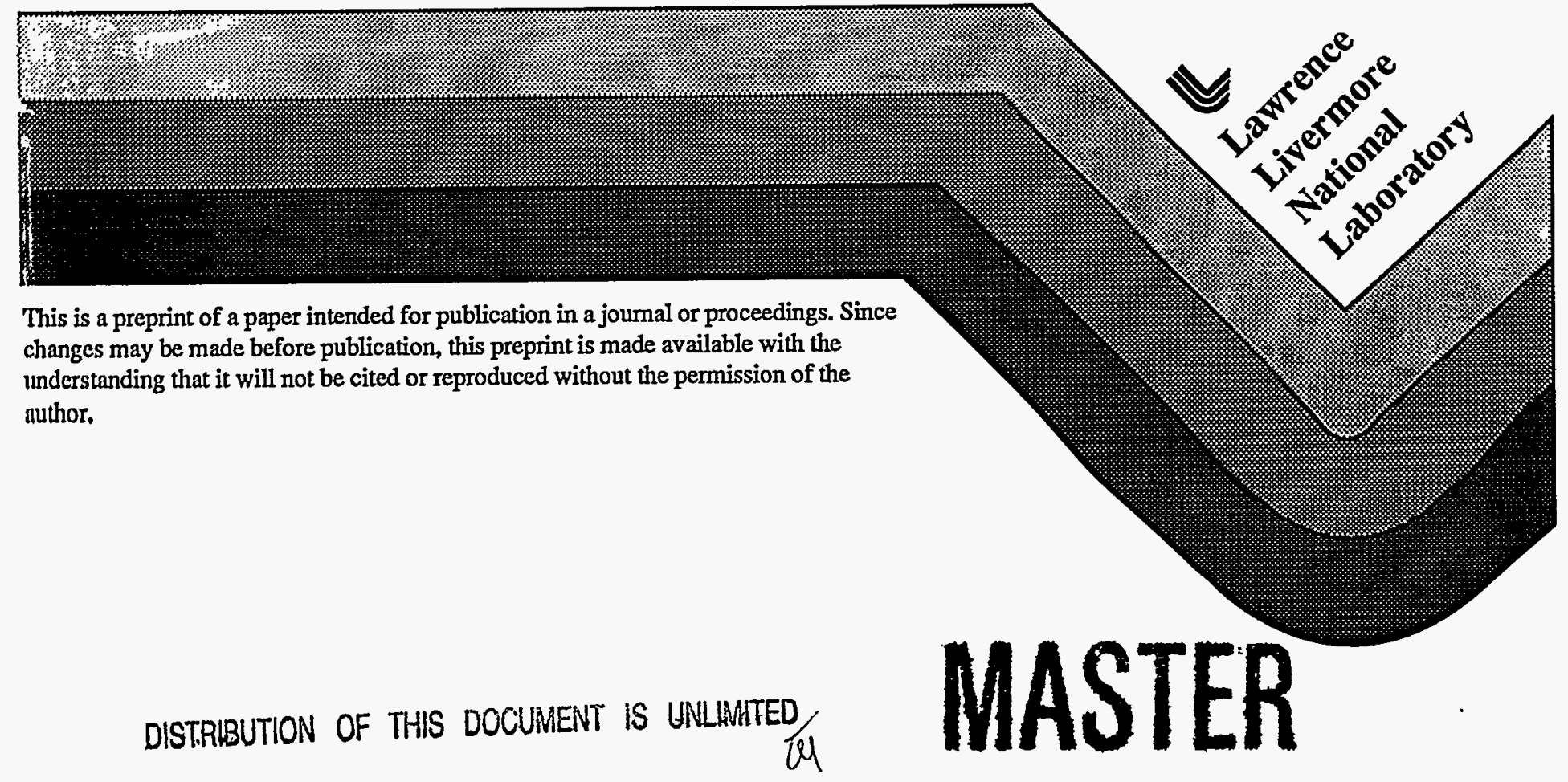




\section{DISCLAIMER}

This document was prepared as an account of work sponsored by an agency of the United States Government. Neither the United States Government nor the University of California nor any of their employees, makes any warranty, express or implied, or assumes any legal liability or responsibility for the accuracy, completeness, or usefulness of any information, apparatus, product, or process disclosed, or represents that its use would not infringe privately owned rights. Reference herein to any specific commercial product, process, or service by trade name, trademark, manufacturer, or otherwise, does not necessarily constitute or imply its endorsement, recommendation, or favoring by the United States Government or the University of California. The views and opinions of authors expressed herein do not necessarily state or reflect those of the United States Government or the University of California, and shall not be used for advertising or product endorsement purposes. 


\section{DISCLAIMER}

Portions of this document may be illegible in electronic image products. Images are produced from the best available original document. 


\title{
AN IN SITU ELECTRON MICROSCOPY TECHNIQUE FOR THE STUDY OF THERMALLY ACTIVATED REACTIONS IN MULTILAYERED MATERIALS
}

\author{
M.A. WALL, T.W. BARBEE, Jr. and T.P. WEIHS \\ Chemistry and Materials Science Department, L-350 \\ Lawrence Livermore National Laboratory \\ Livermore, CA. 94550
}

\begin{abstract}
A novel in situ transmission electron microscopy technique for the observation of reaction processes in multilayered materials is reported. The technique involves constant heating rate experiments of multilayered materials in image and diffraction modes. Because the fine scale microstructure of multilayered materials is typically a small fraction of the TEM specimen thickness, realistic comparison of the microstructural evolution with that of similarly processed thick foil samples is possible. Such experiments, when well designed, can provide rapid characterization of phase transformations and stability of nano-structured materials. The results of these experiments can be recorded in both video and micrograph format. The results and limitations of this technique will be shown for the $\mathrm{Al} / \mathrm{Zr}$ and $\mathrm{Al} / \mathrm{Monel}$ multilayered systems.
\end{abstract}

\section{INTRODUCTION}

The success of transmission electron microscopy (TEM) as a characterization tool in providing the link between a materials microstructure and physical properties is due to its unparalleled spatial resolution. However, one limitation of conventional TEM is that most observations are only static or "post-mortem", allowing only indirect conclusions about the mechanisms of microstructural evolution. In situ HVEM techniques allow for the possibility of overcoming this limitation through direct observation of materials under dynamic conditions [1]. The development and success of in situ experiments hinge upon the proper use and development of instrumentation, specimen preparation and sample design.

Multilayer structures are synthetic, alternately layered, fine-structured materials and fall into a special class called nanostructures. These materials are not only of scientific interest but also are increasingly found to have direct technological applications. This interest is due to their enhanced physical properties. Characterization of the microstructure of these materials is the key to understanding and tailoring their properties. Because of the fine-scale microstructure produced during the synthesis of these materials, TEM is an ideal tool for characterization of these structures. With the fine structural scale of nanostructured materials being of a comparable length scale of the TEM specimen thickness, the ability to compare the dynamic reaction in a thin foil to bulk behavior becomes more realistic. The static characterization of multilayers and thin films has received considerable attention; [2-4] are recent examples. The majority of dynamic in situ TEM experiments performed on these types of materials has been related to heating of the microstructure in order to observe stability and phase transformations. Sinclair [5] reviews a number of successful in situ TEM heating experiments of thin films and multilayers; most of these notable experiments were for specimens viewed in cross-section. These cross-sectional experiments are very labor intensive; preparation of specimens and a heating experiments take many hours or days to perform.

The in situ technique which we describe here is considerably less labor and time intensive. A number of plan view specimens can be made in an hour and contain an order of magnitude more electron transparent area than cross-sectional specimens. An individual constant heating rate experiment may only take 5 to 30 minutes to complete. It will also be shown that results of these in situ experiments are equivalent to similarly processed thick samples. 


\section{MATERIALS AND METHODS}

The sample materials are $\mathrm{A} / \mathrm{Zr}$ and $\mathrm{Al} / \mathrm{M}(\mathrm{Monel}-\mathrm{Ni} 30 \mathrm{at} \% \mathrm{Cu})$ multilayer foils. The bulk stoichiometry, multilayer period and total thickness for the $\mathrm{Al} / \mathrm{Zr}$ and $\mathrm{Al} / \mathrm{M}$ multilayers are: $\mathrm{Al}_{3} \mathrm{Zr}$, $42 \mathrm{~nm}, 41 \mu \mathrm{m}$ and $\mathrm{Al}_{1} \mathrm{M}_{1}, 70 \mathrm{~nm}, 43 \mu \mathrm{m}$ respectively. The reactivity of $\mathrm{Al}$ with Monel is expected to be equivalent to the Al-Ni system. The multilayer foils were synthesized by planar magnetron sputter deposition on to glass substrates. In situ specimens were prepared by the conventional plan view techniques of electropolishing and ion milling. The in situ heating experiments were performed on a JEOL 200CX. A heating holder was fitted to a specially built controller with temperature feed back in order to control the heating rate. Experiments were recorded in both video and micrograph format.

\section{EXPERIMENTAL}

\section{A. Sample design}

In designing a multilayer for in situ TEM heating, several parameters were considered. Layering materials, repeat period and total film thickness were our critical parameters. The selection of $\mathrm{Al}$ with $\mathrm{Zr}$ and Monel is due to the interest in their highly reactive narure. The period of the multilayers was kept below $100 \mathrm{~nm}$ so that several periods would be contained within the electron transparent region of the TEM specimens. The total thicknesses of the foils were increased considerably over most other traditional films to facilitate handling and use in other characterization instruments, such as a differential scanning calorimetry (DSC).

\section{B. Specimen preparation}

For our in situ experiments a combination of traditional preparation techniques were urilized. $3 \mathrm{~mm}$ discs were extracted by spark cutting or disc punching from free standing multilayer foils. The discs were then electropolished to perforation using a solution of $90 \%$ Methanol, 9.5\% Sulfuric acid and $0.5 \%$ Hydrofluoric acid. The electropolishing parameters used were $-25^{\circ} \mathrm{C}$ and $25 \mathrm{~V}$. Specimens were then ion milled under low power conditions; $2-3 \mathrm{kV}, .1-.2 \mathrm{~mA}$ and a $10^{\circ}$ angle of incidence. Ion milling removes any organic contamination, smooths out any etching effects from polishing and removes the thinnest regions which are typically bent and will continue to bend during heating.

\section{In situ heating}

Specimens were mounted in a single tilt heating holder between $\mathrm{Cu}$ washers. The $\mathrm{Cu}$ washers facilitate the heat transfer from the furnace to the thin regions of the specimen. The heating rates can be varied from 1 to $100^{\circ} \mathrm{C} / \mathrm{min}$ while heating to $700^{\circ} \mathrm{C}$ using a process temperature controller. These rates are similar to the heating rates used during DSC studies. The experiments performed were viewed in bright field $(B F)$ and selected area diffraction (SAD) mode. Experiments were recorded using a TV rate CCD camera connected to a Hi-8 format recorder. TEM was performed on the as- deposited and the in situ heated structures. When intermediate transformations were observed additional heating experiments were performed under similar conditions but the heating was ended near or just beyond the reaction temperature. TEM characterization could then be performed on these intermediate reactions. To validate the in situ results $3 \mathrm{~mm}$ diameter multilayer foil samples of $\mathrm{Al} / \mathrm{Zr}$ and $\mathrm{Al} / \mathrm{M}$ were in situ TEM heated under similar conditions. The specimens were then thinned for TEM observation and compared to the in size thin foil specimens.

\section{RESULTS}

\section{ALUMINUM/ZIRCONIUM}

Plan view TEM specimens from an $\mathrm{Al} / \mathrm{Zr}$ multilayer sample were heated in sizu ar a constant heating rate of $50^{\circ} \mathrm{C} / \mathrm{min}$. from room temperature to $725^{\circ} \mathrm{C}$. Separate heating experiments were performed under identical conditions; one in bright field and another in SAD mode. Simulnaneous 
playback of these two experiments showed a correlation between morphological changes in the image mode and crystal structure changes in the diffraction mode. The first transformation started at $=360^{\circ} \mathrm{C}$ and was completed by $=420^{\circ} \mathrm{C}$. A second ransformation started at $=660^{\circ} \mathrm{C}$ and was completed by $=710^{\circ} \mathrm{C}$. A second set of $\mathrm{BF}$ and $\mathrm{SAD}$ mode in situ heating experiments were performed at a $50^{\circ} \mathrm{C} / \mathrm{min}$. to $375^{\circ} \mathrm{C}$, just beyond the start of the first transformation.

TEM characterization of the BF and SAD mode heating experiments is as follows. The plan view as-deposited structure consists of a bimodal grain size. The larger grains $(\approx 50 \mathrm{~nm}$ diam.) are the pure Al FCC phase and the finer grains ( $=10 \mathrm{~nm}$ diam.) are the pure $\mathrm{Zr} \mathrm{HCP}$ phase, Fig.1a. Upon heating through the first reaction a uniform, fine grain size $(=20 \mathrm{~nm})$, metastable $\mathrm{Al}_{3} \mathrm{Zr}_{\mathrm{I}}$ cubic phase has appeared, Fig. 1b. Continued heating through the second transformation resulted in the nucleation and growth of a larger grain size $(\approx 200 \mathrm{~nm})$, stable, $A I_{3} \mathrm{Zr}$ tetragonal phase and a minor amounts of $\mathrm{Al}_{2} \mathrm{Zr}$, Fig.1c.
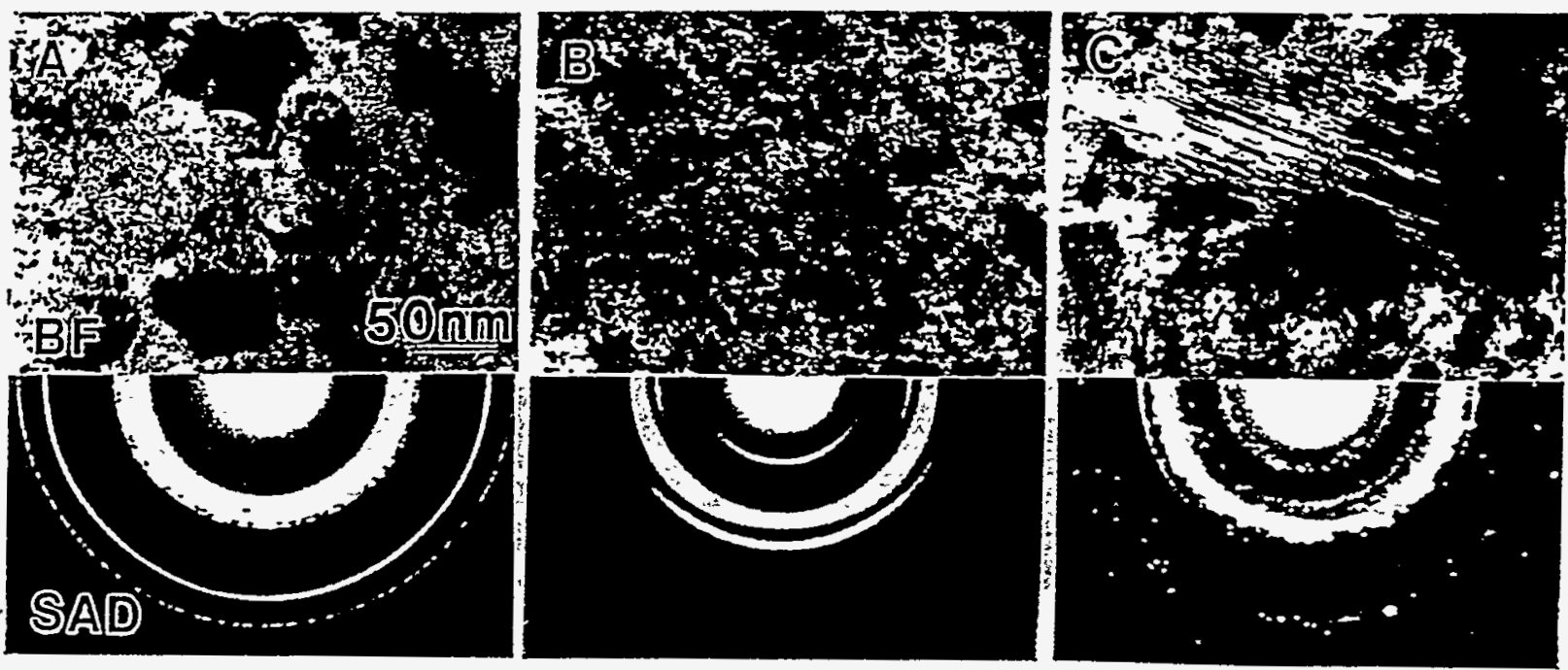

Fig. 1, BF and $S A D$ results of in situ hearing of $A l / Z$ r thin foil specimens, $A$ ) Elemental $A l$ and $Z r$, B) Cubic $\mathrm{Al}_{3} \mathrm{Zr}$ at $50^{\circ} \mathrm{C} / \mathrm{min}$. to $360^{\circ} \mathrm{C}$, C) Tetragonal $\mathrm{Al}_{3} \mathrm{Zr}$ at $50^{\circ} \mathrm{C} / \mathrm{min}$. to $600^{\circ} \mathrm{C}$. All $\mathrm{BF}$ micrographs are at the same magnification.

\section{ALUMINUMMONEL}

In similar fashion as the $A l / Z r$, plan view TEM specimens from an $A l / M$ multilayer sampie were heated in situ at a constant rate of $50^{\circ} \mathrm{C} / \mathrm{min}$. to a temperature of $700^{\circ} \mathrm{C}$ in both $\mathrm{BF}$ and SAD TEM modes. Again, simultaneous playback of the recorded experiments showed a direct correspondence between microstrucural and diffraction pattern changes. Two low temperamure transformations were observed at $=250^{\circ} \mathrm{C}$ and $=350^{\circ} \mathrm{C}$ with the end of the first transiormation overlapping considerably with the beginning of the second. A third higher temperature transformation occurred at $=500^{\circ} \mathrm{C}$. Two additional BF and SAD mode constant heating rale in siru experiments were then performed; one to the first reaction at $250^{\circ} \mathrm{C}$, a second to $400^{\circ} \mathrm{C}$.

TEM characterization of the $\mathrm{BF}$ and $\mathrm{SAD}$ mode heating experiments is as follows. The asdeposited structure consists of a bimodal grain size distribution of pure FCC AI ( $=20 \mathrm{~nm}$ diam.) and FCC Monel ( $\approx 10 \mathrm{~nm})$, Fig.2a. Upon heating to the first reaction FCC Al is no longer present and a number of new $\mathrm{Al}$ rich phases have appeared; $\mathrm{Al}_{3} \mathrm{M}, \mathrm{Al}_{2} \mathrm{M}$ and small amount of $\mathrm{Al}_{3} \mathrm{M}_{2}$; Monel is still present, Fig.2b. Heating through the second transformation resulted in the formation of $\mathrm{Al}_{3} \mathrm{MI}_{2}$ with some Monel remaining, Fig. 2c. Heating through the final transformarion temperature resulted in the formation of $\mathrm{Al}_{1} \mathrm{M}_{1}$, identical to the $\mathrm{Al}_{1} \mathrm{Ni}_{1} \mathrm{~B} 2$ compound, Fig. $2 \mathrm{~d}$.

\section{THICK SAMPLE HEATING}

Prior to preparation for TEM observation, thick foil multilayer samples of $A 1 / Z$ r and $A L / M$ 
were constant-rate heated in sim in the IEM to temperatures closely corresponding to the different reaction temperatures seen in the previous in situ thin foil specimen experiments. Figures 3 and 4 show the results of the TEM characterization of these thick foil hearing experiments. For both the $\mathrm{Al} / \mathrm{Zr}$ and $\mathrm{Al} / \mathrm{Monel}$ systems there is a close correspondence of morphology and product phase formation to the in situ thin foil specimen heating.

To compare our in situ results to conventional characterization techniques, thick multilayer foil samples were constant rate heared in a Differential Scanning Calorimeter to obtain exothermic reaction temperatures. After initial DSC reactions were observed additional samples were DSC heated to intermediate reaction temperatures then cooled back down to room temperamure. $X$-ray diffraction was then performed on the DSC heated foils to determine the phases that where present after each reaction temperanure. A detailed report of the DSC and X-ray diffraction study on the reactivity and phase formation in these multilayer systems is reported by [6-7]. There is very good agreement berween the reported DSCK-ray results and this TEM data.
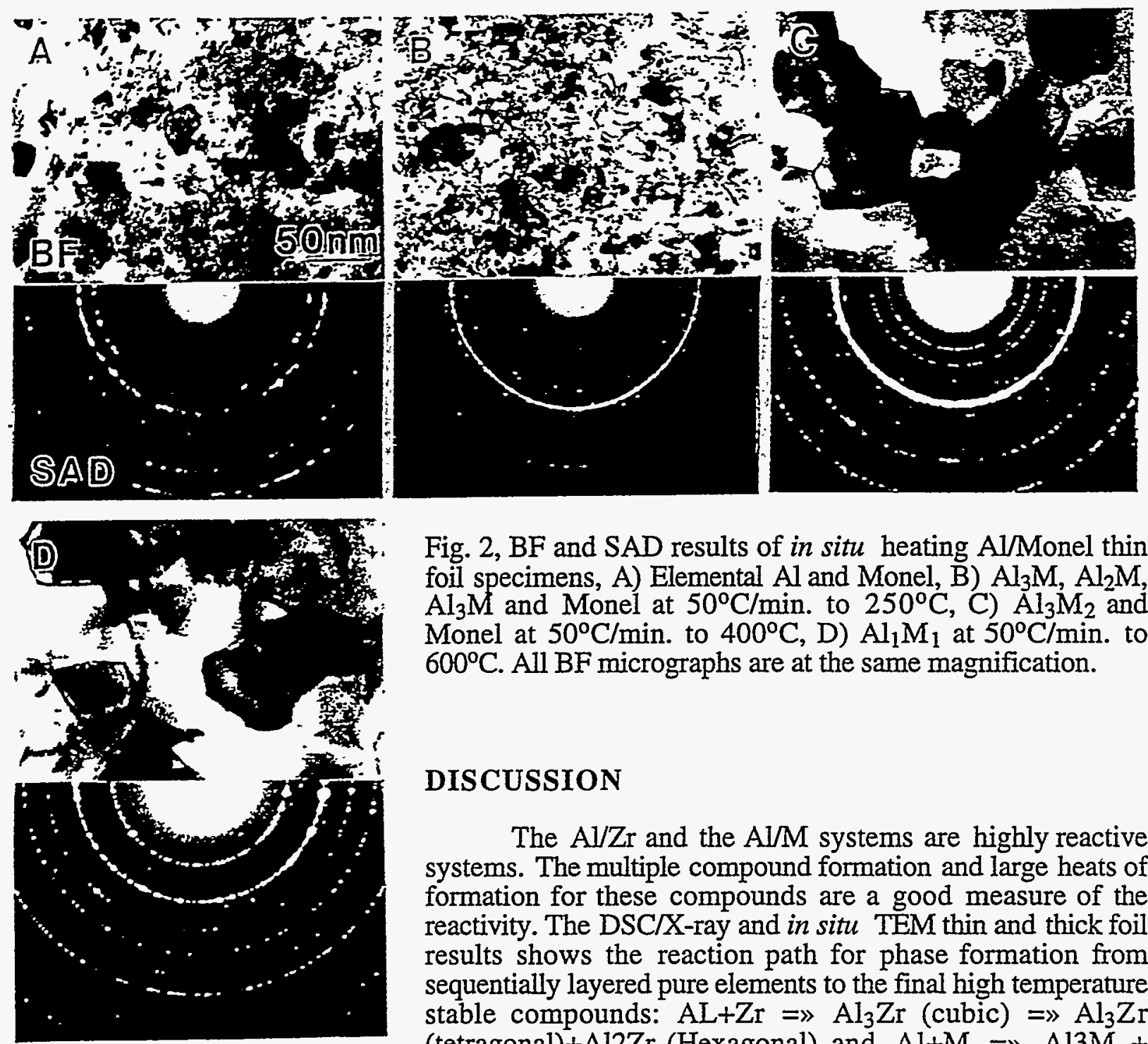

Fig. 2, BF and SAD results of in situ heating Al/Monel thin foil specimens, A) Elemental $\mathrm{Al}$ and Monel, $\mathrm{B}$ ) $\mathrm{Al}_{3} \mathrm{M}, \mathrm{Al}_{2} \mathrm{M}$, $\mathrm{Al}_{3} \mathrm{M}$ and Monel at $50^{\circ} \mathrm{C} / \mathrm{min}$. to $\left.250^{\circ} \mathrm{C}, \mathrm{C}\right) \mathrm{Al}_{3} \mathrm{M}_{2}$ and Monel at $50^{\circ} \mathrm{C} / \mathrm{min}$. to $400^{\circ} \mathrm{C}$, D) $\mathrm{Al}_{1} \mathrm{M}_{1}$ at $50^{\circ} \mathrm{C} / \mathrm{min}$. to $600^{\circ} \mathrm{C}$. All BF micrographs are at the same magnification.

\section{DISCUSSION}

The $\mathrm{Al} / \mathrm{Zr}$ and the $\mathrm{Al} / \mathrm{M}$ systems are highly reactive systems. The multiple compound formation and large heats of formation for these compounds are a good measure of the reactivity. The DSC/X-ray and in situ TEM thin and thick foil results shows the reaction path for phase formation from sequentially layered pure elements to the final high temperature stable compounds: $\mathrm{AL}+\mathrm{Zr}=\gg \mathrm{Al}_{3} \mathrm{Zr}$ (cubic) $=\gg \mathrm{Al}_{3} \mathrm{Zr}$ (tetragonal)+Al2Zr (Hexagonal) and $\mathrm{Al}+\mathrm{M}=\mathrm{Al} 3 \mathrm{M}+$ $\mathrm{Al}_{2} \mathrm{M}+\mathrm{Monel} \Rightarrow \mathrm{Al}_{3} \mathrm{M}_{2}+$ Monel $\Rightarrow \mathrm{Al}_{1} \mathrm{M}_{1}$. Cross-sectional TEM revealed a thin amorphous reaction layer at the $A 1 / Z$ r interfaces [7]. The intensity of diffraction pattern from this small volume is too weak to be observed in the plan view TEM speicmens.

The success of our in situ TEM constant heating rate experiments in obtaining results comparable to bulk foil in situ heating and conventional DSC heating is due to several factors. First, by orientating the multilayer specimens in plan view the interfaces between the pure elemental layers 

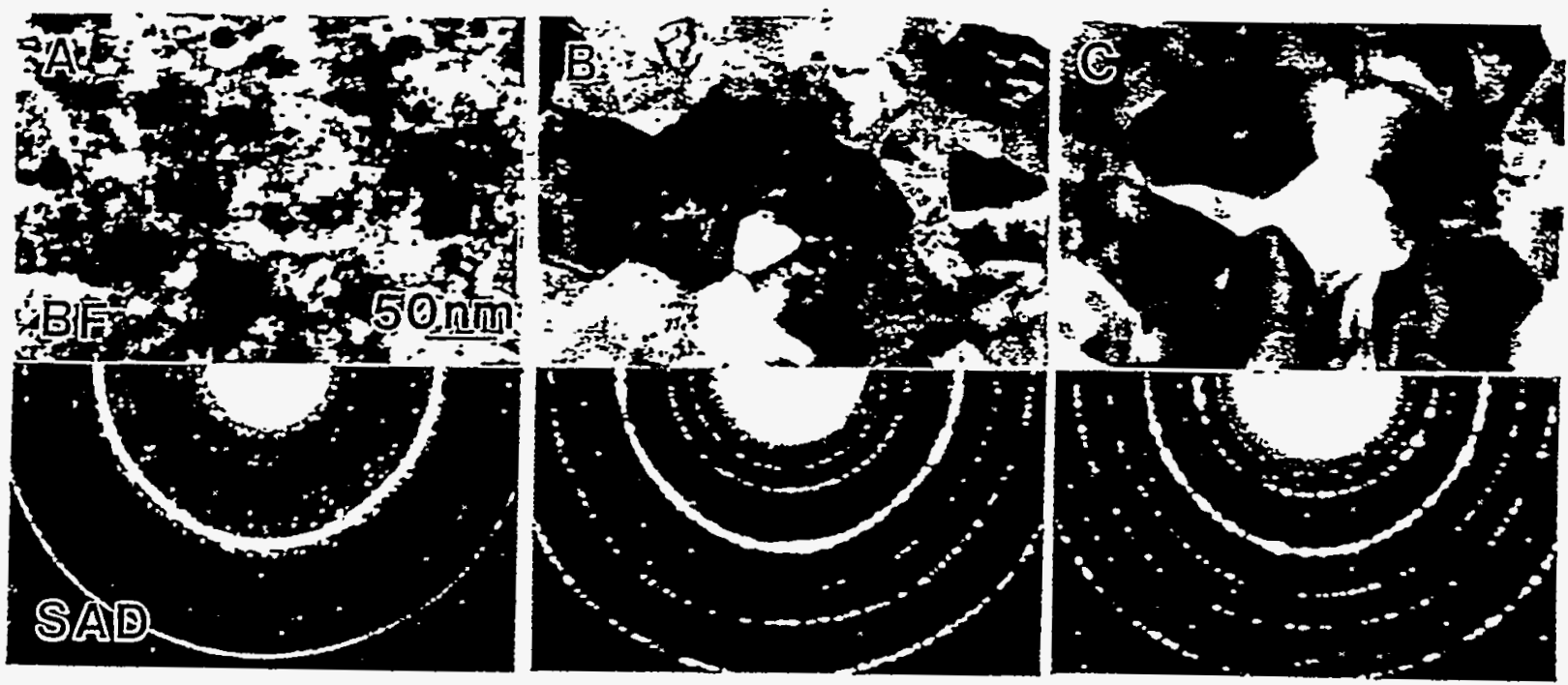

Fig. 3, BF and $S A D$ results of hearing thick foil $A 1 /$ Monel samples, $A$ ) $A l_{3} M+A l_{2} M \div$ Monel at $50^{\circ} \mathrm{C} / \mathrm{min}$. to $\left.275^{\circ} \mathrm{C}, \mathrm{B}\right) \mathrm{Al}_{3} \mathrm{M}_{2}+\mathrm{Al}_{3} \mathrm{M}+\mathrm{M}$ onel at $50^{\circ} \mathrm{C} / \mathrm{min}$. to $\left.450^{\circ} \mathrm{C}, \mathrm{C}\right) \mathrm{Al}_{1} \mathrm{M}_{1}$ at $50^{\circ} \mathrm{C} / \mathrm{min}$. to $600^{\circ} \mathrm{C}$.

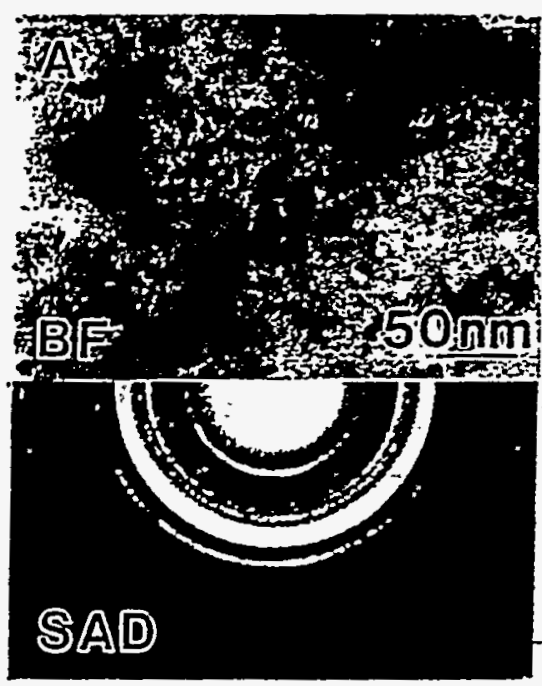

Fig. 4, BF and $S A D$ results of heating thick foil $A 1 / \mathrm{Zr}$ samples, A) Cubic $\mathrm{Al}_{3} \mathrm{Zr}$ at $50^{\circ} \mathrm{C} / \mathrm{min}$. to $375^{\circ} \mathrm{C}, \mathrm{B}$ ) Tetragonal $\mathrm{Al}_{3} \mathrm{Zr}$ at $50^{\circ} \mathrm{C} / \mathrm{min}$. $10720^{\circ} \mathrm{C}$. All micrographs are at the same magnification.
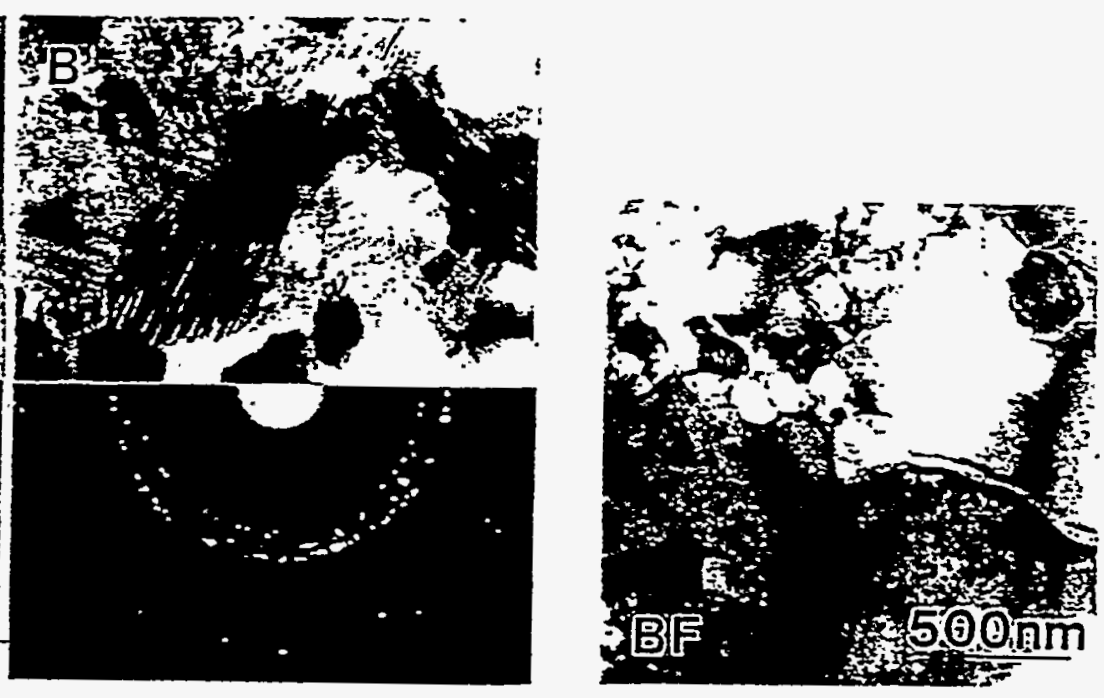

Fig. 5, BF micrograph showing larger grains in the thicker region and small grains in the thinner regions. $\mathrm{Al} / \mathrm{Mat} 725^{\circ} \mathrm{C}$.

are contained within the electron transparent region. DSC studies [7] indicate that diffusion in these systems is primarily one dimensional, perpendicular to the interfaces. If the mulitaver specimens are oriented in cross-secrion then the multilayer interfaces contained in the foil are small in area and are short circuited to the surfaces of the specimen. Vacancies, which are necessary to support the diffusion process, may be lost by boundary diffusion to the surface of the specimen foil in cross-sectioned specimens. This will slow or impede any reaction. Secondly, plan view specimens typically have many times more electron transparent area as do cross-sectional specimens. thus increasing significantly the staistical sampling of the diffraction data. Finally, plan view specimens are also easier and faster to prepare for TEM observation than cross-sectional specimens: many experiments can be run in a snort period of time, thus increasing the confidence levei of the data. In situ cross-sectional experiments do have the advantage of observing the locarion at which new phases nucleate and grow with respect to the interfaces. 
Performing these experiments with multilayer samples having small periods ( $<100 \mathrm{~nm})$ insures that several layers and interfaces will be contained within the electron transparent area With larger periods, the possibility of not having one complete period in the specimen exists. It is also possible that for larger period samples or thin specimens that a non-integral number of periods (ie; $3.5,6.5 \ldots$...) will be contained in the specimen. With smaller periods and thicker specimens the local compositional error from an extra one-half layer becomes increasingly small. A final limitation of these in situ experiments is that the specimen thickness may limit the final grain size of the reaction product phases, Fig. 5. This becomes more pronounced at higher temperatures where grain growth occurs. After viewing a number of experiments, it was observed that the reaction temperatures in the TEM' were sometimes higher than expected from the DSC results. There is always the concem of the conduction of heat through a thin specimen foil to achieve a temperature in the electron transparent region that is similar to that of the thermocouple contact point on the furnace.

\section{CONCLUSION}

We have described a technique for the dynamic observation of the microstructural evolution in reactive multilayer systems: $A l / Z$ and $A 1 / M o n e l$. The results of this technique were validated by the similar heating of thick foil samples and then observing in TEM. This TEM data is also comparable to DSC and X-ray characterization studies performed on these same two alloy systems. This technique is relatively fast and simple to perform. However, the thin foil may limit the final grain size at high temperatures and the heat flow through a thin sample sometimes is slowed. When applied to fine scale structures these in situ experiments can yield rapid TEM results comparable and complementary to the combination of DSC and X-ray diffraction.

\section{ACKNOWLEDGEMENTS}

The authors wish to thank Richard Gross of Lawrence Livermore National Laboratory for his technical support. This work was performed under the auspices of the US Department of Energy by the Lawrence Livermore National Laboratory under contract W-7405-Eng- 48 .

\section{REFERENCES}

1) E. P. Butler, Proceedings of the 38th Electron Microscoov Society of America. (Claton Publishing Div., Baton Rouge, Louisiana,1980) p. 12.

2) C.S. Baxter and W.M. Stobbs, Ultramicroscopy, 16, 213 (1985).

3) J.W. Matthews and A.E. Blakeslee, J. of Crystal Growth, 27, 118 (1974).

4) T. Nguyen, R. Gronsky, and B. Kortright, Proc. from the 5th Pacific Electron Microscodv Conference, Electron Microscopy 1, World Scientific Publishers, New Jersey, 1992), p. 616.

5) R. Sinclair, Proceedings of the 47th Annual Meeting of the Electron Microsconv Socierv of America, (San Francisco Press, San Francisco, CA, 1989), p. 638.

6) T.W. Jr. Barbee, M. A. Wall, and T. P. Weihs, presented at 1995 MRS Spring Meeting, Sym. G, San Francisco, CA, (1995)

7) K.J. Blobaum, T.P. Weihs, T.W. Jr.Barbee and M.A. Wall, presented at 1995 MRS Spring Meeting, Sym. G, San Francisco, Ca. (1995). 